\title{
Comparative conventional- and quantum dot-labeling strategies for LPS binding site detection in Arabidopsis thaliana mesophyll protoplasts
}

\author{
Londiwe S. Mgcina, Ian A. Dubery and Lizelle A. Piater* \\ Department of Biochemistry, University of Johannesburg, Johannesburg, South Africa
}

OPEN ACCESS

Edited by:

Andrea Genre,

University of Turin, Italy

Reviewed by:

Brigitte Mauch-Mani,

Université de Neuchâtel, Switzerland

Sergei Svarovsky,

Xen Biofluidx Inc., USA

*Correspondence:

Lizelle A. Piater,

Department of Biochemistry,

University of Johannesburg, Corner

of Kingsway and University Road,

Auckland Park 2006, Johannesburg,

Gauteng, South Africa Ipiater@uj.ac.za

Specialty section:

This article was submitted to

Plant-Microbe Interaction,

a section of the journal

Frontiers in Plant Science

Received: 16 February 2015

Accepted: 28 April 2015

Published: 12 May 2015

Citation:

Mgcina LS, Dubery IA and Piater LA (2015) Comparative conventionaland quantum dot-labeling strategies

for LPS binding site detection

in Arabidopsis thaliana mesophyll

protoplasts.

Front. Plant Sci. 6:335

doi: 10.3389/fpls.2015.00335
Lipopolysaccharide (LPS) from Gram-negative bacteria is recognized as a microbeassociated molecular pattern (MAMP) and not only induces an innate immune response in plants, but also stimulates the development of characteristic defense responses. However, identification and characterization of a cell surface LPS-receptor/binding site, as described in mammals, remains elusive in plants. As an amphiphilic, macromolecular lipoglycan, intact LPS potentially contains three MAMP-active regions, represented by the O-polysaccharide chain, the core and the lipid A. Binding site studies with intact labeled LPS were conducted in Arabidopsis thaliana protoplasts and quantified using flow cytometry fluorescence changes. Quantum dots (Qdots), which allow noncovalent, hydrophobic labeling were used as a novel strategy in this study and compared to covalent, hydrophilic labeling with Alexa 488. Affinity for LPS-binding sites was clearly demonstrated by concentration-, temperature-, and time-dependent increases in protoplast fluorescence following treatment with the labeled LPS. Moreover, this induced fluorescence increase was convincingly reduced following pre-treatment with excess unlabeled LPS, thereby indicating reversibility of LPS binding. Inhibition of the binding process is also reported using endo- and exocytosis inhibitors. Here, we present evidence for the anticipated presence of LPS-specific binding sites in Arabidopsis protoplasts, and furthermore propose Qdots as a more sensitive LPS-labeling strategy in comparison to the conventional Alexa 488 hydrazide label for binding studies.

Keywords: defense, flow cytometry, innate immunity, lipopolysaccharides (LPSs), LPS-binding sites, LPS-labeling, microbe-associated molecular pattern (MAMP), protoplasts

\section{Introduction}

Lipopolysaccharides (LPSs) are complex lipoglycans found in the outer membrane of Gramnegative bacteria and is generally composed of three regions namely the fatty acid lipid A disaccharide, a core region of short oligosaccharide chains and an $\mathrm{O}$-antigen region of polysaccharides (Madala et al., 2011, 2012). This composition, however, varies among different bacterial species and strains. The O-antigen moiety may be shortened or absent to result in a more hydrophobic molecule (rough LPS), while smooth LPS has a more amphiphilic nature due to a repetitive glycan polymer. 
Lipopolysaccharide elicits toxic- and inflammatory responses in mammals due to lipid A, lipid A precursors and the covalentlylinked core region which possess immunogenic properties (Silipo et al., 2005). This potent biological response to LPS is triggered via receptor-mediated recognition. Here, LPS binds to a LPS binding protein (LBP) to form a LPS-LBP complex which is translocated to myeloid differentiation 2 (MD2) with the presence/absence of its co-receptor, a glycosylphosphatidylinositol (GPI)-linked protein, CD14 (Triantafilou et al., 2001; Sasaki and White, 2008). The interaction occurs on the host membrane, and triggers a signaling cascade activated by the interaction with Toll-like receptor 4 (TLR4; Triantafilou et al., 2001; Scott et al., 2009). The latter, a leucine-rich repeat (LRR) protein, acts as a pattern-recognition receptor (PRR) for perception of LPS as a microbe-associated molecular pattern (MAMP) molecule, and initiates transduction of ligand-specific perception, subsequent signaling cascades and the activation of an immune response (Nürnberger et al., 2004; Albright et al., 2009; Betanzos et al., 2009).

Lipopolysaccharide is recognized as "non-self" (Van Loon et al., 1998; Sanabria et al., 2008; Dubery et al., 2012) and has, to date, been shown to act as a MAMP which induces defense responses in plants (Coventry and Dubery, 2001; Zeidler et al., 2004; Erbs and Newman, 2012). These include activation of an oxidative burst characterized by the release of reactive oxygen species (ROS), a nitric oxide (NO) burst, an influx of $\mathrm{Ca}^{2+}$ ions, extracellular medium alkalinization and reversible protein phosphorylation via mitogen-activated protein kinases (MAPKs; Gerber et al., 2004, 2006; Piater et al., 2004; Zeidler et al., 2004), resulting in activation of defense genes (Zeidler et al., 2004; Madala et al., 2011, 2012). Increased expression of receptorlike kinases (RLKs), such as the rapid biphasic induced-response of Nt-Sd-RLK (Sanabria et al., 2012) has also been reported. Systemic acquired resistance (SAR) is furthermore known to be triggered by LPS elicitation through in the expression of $P R$ genes in upper leaves upon lower leaf treatment (Coventry and Dubery, 2001; Zeidler et al., 2004; Mishina and Zeier, 2007). Such defense components lead to heightened plant sensitivity to subsequent stimuli and microbe sensing, thus termed a primed state (Newman et al., 2007; Sanabria et al., 2008; Madala et al., 2012).

The mechanism whereby plants perceive LPS is, however, not known, and all three structural components have similarly been shown to induce defense responses (Erbs and Newman, 2012; Madala et al., 2012). This thus questions the sole role of lipid A as seen in mammalian perception and introduces a focus on other LPS subcomponents. Furthermore, it would be incorrect to assume that LPS passively diffuses through the plant cell plasma membrane due to its large size and amphipathic nature (Gross et al., 2005), and thus it most likely interacts with a surface-localized receptor or receptor complex as the primary binding site. Here, two modes of perception are possible, namely direct recognition and binding of the LPS by a PRR(s), or indirectly as a result of ligandinduced conformational changes, dimerization, and/or recruitment of a co-receptor. The latter then results in auto- and trans-phosphorylation of the receptor as well as other proteins
(Altenbach and Robatzek, 2007; Chinchilla et al., 2007; Zipfel, 2009).

A number of LPS-labeling strategies have been employed. In conjunction with flow cytometry, 4,4-difluoro-4-bora-3a,4adiaza-s-indacene [or boron-dipyrromethene (BODIPY)], as well as Alexa 488 hydrazide, biotin, and fluorescein isothiocyanate (FITC), have successfully been used in mammalian studies (Odeyale and Kang, 1988; Triantafilou et al., 2000; Betanzos et al., 2009). In comparison, FITC-labeling was investigated in plant cells (Nicotiana tabacum) in endocytosis investigations of LPS from Xanthomonas campestris pv. campestris (Gross et al., 2005), while Alexa 488-labeling was employed in mobility studies of LPS from Salmonella minnesota in Arabidopsis. These approaches modify chemical groups (particularly the hydroxyl groups of the $\mathrm{O}$-antigen) upon conjugation. Pathogens that lack an O-antigen, such as $X$. campestris pv. campestris, have a rough LPS component and since Alexa 488 hydrazide readily interacts with hydrophilic components, labeling is impossible due to smooth LPS being preferred (Triantafilou et al., 2000). As such, an alternative labeling strategy is required like the use of quantum dots (Qdots). Betanzos et al. (2009) described the labeling of both lipid A and lipoglycan (LPSs from Escherichia coli and Pseudomonas aeruginosa) using Qdot-conjugation through hydrophobic interactions.

Since most LPS labels, including Qdots, are fluorophores, flow cytometry can be used for quantification of cell-ligand binding interactions through the analysis of optical properties such as fluorescence and light scatter at a specific emission wavelength. This technique, however, requires single cells, and thus the production of protoplasts from higher plant tissues (Galbraith, 1994; Doležel et al., 2007; Yoo et al., 2007).

In this study we compare LPS-labeling with Alexa 488 to Qdots as covalent and non-covalent hydrophobic conjugating strategies respectively, for binding studies in Arabidopsis thaliana mesophyll protoplasts. Besides comparison between these, more notably we report for the first time, both conjugates showed affinity for LPS-specific binding sites. Inhibitor studies furthermore suggest that the binding site-ligand interaction may be subject to binding site recycling via endo- and exocytosis processes similar to that reported for MAMP receptors (Zipfel, 2014).

\section{Materials and Methods}

\section{Protoplast Isolation and Determination of Viability}

Seeds of $A$. thaliana (Columbia ecotype) were planted in soil and allowed to germinate in an environment-controlled plant growth room at $24^{\circ} \mathrm{C}$ with a $8 \mathrm{~h}$ light $/ 16 \mathrm{~h}$ dark photoperiod to generate mature plants. For protoplast isolation, $2 \mathrm{~g}$ A. thaliana leaves were cut into 1-2 mm strips and the protocol according to Yoo et al. (2007) was followed using enzymatic digestion with a solution containing cellulase "Onosuka"R10, macerozyme R10 (Yakult Pharmaceutical Industry, Tokyo, Japan) and pectinase (Sigma, St. Louis, MO, USA). Micrographs were taken to show the disintegration of clumped protoplasts at regular $30 \mathrm{~min}$ intervals for $2 \mathrm{~h}$. The obtained protoplasts were resuspended 
in $5 \mathrm{ml} \mathrm{MMg}$ buffer (0.4 M mannitol; $15 \mathrm{mM} \mathrm{MgCl}_{2} ; 4 \mathrm{mM}$ MES, $\mathrm{pH}$ 5.7) and the concentration determined with the use of a hemocytometer slide (Boeco, Germany) so as to obtain a working concentration of $2 \times 10^{5} / \mathrm{ml}$ at room temperature (RT). The integrity of protoplasts was monitored over a $32 \mathrm{~h}$ time period using the fluorescein diacetate (FDA) stain according to Cheng and Bélanger (2000). A stock solution of $5 \mathrm{mg} / \mathrm{ml}$ FDA was prepared in acetone, and a $2 \times 10^{5} / \mathrm{ml}$ protoplast suspension incubated with $50 \mu \mathrm{g} / \mathrm{ml}$ stain at RT for $10 \mathrm{~min}$. Protoplast micrographs were taken on a Carl Zeiss fluorescent microscope under 430-490 nm fluorescence filters, and live (yellow) and dead (red) protoplasts viewed and counted (Fernandez-DaSilva and Yuffa, 2006).

\section{Lipopolysaccharide-Labeling and Characterization}

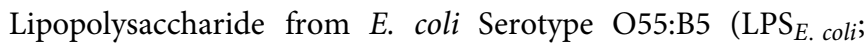
Sigma, St. Louis, MO, USA), Alexa Fluor ${ }^{\circledR} 488$ conjugate (AlexaLPS $_{\text {E. coli; }}$ Eugene, Oregon, USA), and Qdot 605 ITK in decane (Invitrogen) were used for the investigations. The commer-

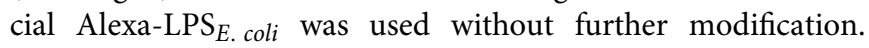
Conjugation of PPS $_{E \text {. coli }}$ to quantum dots (Qdots) was performed according to Morales-Betanzos et al. (2011). This method is reported to have broad applicability in studies that require LPS bio-distribution visualization and in the identification of an LPSbinding site in mammals.

\section{Characterization of Quantum Dot-LPS Conjugates by Transmission Electron Microscopy (TEM) Analysis and Absorbance Spectral Scans}

Several protocols can be employed to characterize Qdot-LPS conjugates, with TEM chosen as the most reliable technique due to visualization of conjugates and the ability to determine the diameter of complexes formed. This analysis was employed in the characterization of Qdot-LPS ${ }_{E \text {. coli }}$ conjugates, $\mathrm{LPS}_{E \text {. coli }}$ in $\mathrm{MMg}$ buffer, and Qdots in chloroform (both latter samples serving as negative controls) since the hydrophobic nature of the organic solvent prevents the formation of micelles (Betanzos et al., 2009). Five $\mu l$ of each sample was placed on a carbon formvar mesh grid, and air dried. Negative staining was employed with the use of uranyl acetate producing a high electron density and image contrast. High resolution images were obtained using an Olympus Veletta camera operating at an acceleration voltage of $200 \mathrm{kV}$ (Department of Microscopy, University of Pretoria, South Africa). Absorbance spectral scans of all samples was also determined using a fluoroscan instrument with excitation set at 485/20 and emission at 590/35 $\mathrm{nm}$.

\section{Quantification of Quantum Dot-LPS Conjugates by 2-Keto-3-Deoxyoctonate (KDO) Determination}

Quantum dot-conjugates can be quantified by molarity and mass concentration of LPS, however, due to size heterogeneity of the lipoglycan not being well defined (personal communication with D. Maysinger, Lalancette-Herbert et al., 2010), it is not possible to determine the exact molar concentration of LPS conjugates. As an alternative, indirect determination of the LPS concentration through the quantification of KDO in the conjugate (Barr et al., 2010) was used as a quantitative marker. This also served to comparatively assess the concentration of LPS bound to Qdots in relation to the Alexa-LPS E. coli binding studies. The KDO assay was performed according to Karkhanis et al. (1978) and the content calculated (Coventry and Dubery, 2001).

\section{Optimization of Protoplast Treatment and Flow Cytometry Measurements}

The variation of several parameters was investigated in order to determine the optimal binding concentration, temperature and

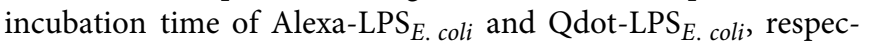
tively, in Arabidopsis mesophyll protoplasts. According to Venis (1985) the ideal concentration range in ligand-receptor studies is that which will saturate between 10 and $90 \%$ of the receptor.

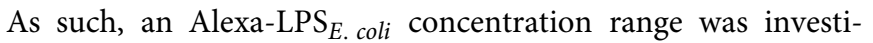
gated between 0.18 and $1.0 \mu \mathrm{g} / \mathrm{ml}$, while that for Qdot-LPS $E_{E \text {. coli }}$ was examined between 0.11 and $0.46 \mu \mathrm{g} / \mathrm{ml}$. These ranges were selected firstly to allow comparison between the alternatively labeled lipoglycan-conjugates. A second consideration was that the critical aggregation concentrations (CACs) of various LPSs are reported to be between 11 and $22 \mu \mathrm{g} / \mathrm{ml}$, and this would lead to clumping of labeled protoplasts and hence impede flow cytometry measurements (Aurell and Wistrom, 1998). Lastly, at FITC-labeled-LPS ${ }_{X . c . c}$ concentrations as low as $5 \mu \mathrm{g} / \mathrm{ml}$ uniform binding on the cell surface was already observed $10 \mathrm{~min}$ posttreatment followed by significant internalization after $30 \mathrm{~min}$ in N. tabacum cell suspensions (Gross et al., 2005). Thus to follow binding over time, a 10-fold lower concentration was selected. The optimal treatment incubation temperature was similarly investigated at $4^{\circ} \mathrm{C}, 20-22^{\circ} \mathrm{C}(\mathrm{RT}), 37^{\circ} \mathrm{C}$ and $65^{\circ} \mathrm{C}$ respectively, whereas the optimal incubation time ranged from 10 to $120 \mathrm{~min}$. In all cases, protoplasts $\left(2 \times 10^{5} / \mathrm{ml}\right)$ were placed on a rotary shaker at $20 \mathrm{rpm}$, with protoplasts in $\mathrm{MMg}$ solution serving as an untreated negative control sample. The mean fluorescence intensity of all the samples was measured on a BD FACS Aria flow cytometer (Becton, Dickenson and Company, Germany) using a $100 \mu \mathrm{m}$ diameter nozzle to accommodate protoplasts with diameters ranging from 30 to $80 \mu \mathrm{m}$, equipped with a blue, red and violet laser. The instrument was excited at $488 \mathrm{~nm}$ by the blue laser and filtered on the FITC channel at bandpass (BP) $530 / 30$ (thus light transmitted between 500 and $560 \mathrm{~nm}$ ) for Alexa-LPS $S_{E \text {. coli }}$ samples, while for Qdot-LPS . coli $_{\text {the Texas Red }}$ channel at BP 610/20 was used (thus light transmitted between 590 and $630 \mathrm{~nm}$ ) to determine the mean fluorescence of each sample. Following optimization, a constant number of events was counted for each analysis and samples are reported relative to the control value which is set at $100 \%$ (the mean fluorescence values of individual controls ranged from 3500 to 28000).

\section{Binding Site Studies}

Binding site studies were performed to investigate (i) concentration-, temperature-, and incubation-time dependence (in vitro controlled parameters), (ii) dose-response relationship and (iii) reversibility of the administered ligand. 
Following optimization of the in vitro parameters with the respective labeled LPS-conjugates, the dose-response relationship was determined by isolating protoplasts and dilution to six concentrations namely $1.2 \times 10^{5}, 2 \times 10^{5}, 4 \times 10^{5}$, $8 \times 10^{5}, 1.2 \times 10^{6}$, and $1.6 \times 10^{6}$ protoplasts $/ \mathrm{ml}$. Here, the option to vary the protoplast- and not LPS-concentration is again ascribed to the CMC and internalization concerns addressed in the optimal concentration studies. The protoplasts were then treated with the determined concentration of labeled LPS as specified in the figure legends. Reversibility of binding was determined by pre-treatment of $2 \times 10^{5}$ protoplasts/ml with unlabeled LPS (up to $100 \mathrm{X}$ excess) for $30 \mathrm{~min}$ at $\mathrm{RT}$ on a rotary shaker set at $20 \mathrm{rpm}$, followed by elicitation with labeled LPS-conjugates (as determined), with negative (unlabeled LPS) and positive (respective labeled LPS $_{E \text {. coli }}$ ) controls for comparison. All resulting data were based on the measured relative fluorescence determined as described.

\section{Exo- and Endocytosis Inhibition of Labeled LPS $_{E \text {. coli }}$ Binding Site Studies}

Based on previous work (Gross et al., 2005; Robatzek et al., 2006; Beck et al., 2012b), it was deemed necessary to determine whether LPS could be endocytosed into the plant cell (protoplast) to trigger the induction of a defense response, or whether the defense response occurs due to interactions with binding site-/receptorlike proteins on the membrane. Fifty $\mu \mathrm{g} / \mathrm{ml}$ Wortmannin in dimethyl sulfoxide (DMSO) and Brefeldin A (BFA) in ethanol respectively, were thus used to investigate endo- and exocytosis inhibition. Co-treatment of protoplasts $\left(2.5 \times 10^{5}\right.$ protoplasts $/ \mathrm{ml}$ in $\mathrm{MMg}$ buffer) involved simultaneous treatment with either

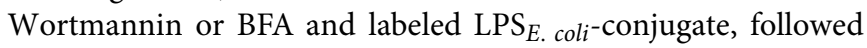
by incubation at RT for $120 \mathrm{~min}$. Sole Wortmannin, BFA and

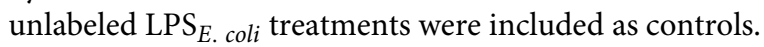

\section{Results and Discussion}

\section{Integrity of Protoplasts following Isolation}

When optimally isolated, protoplasts retain cell integrity as well as original biochemical and physical properties (Galbraith, 1994; He et al., 2006), thus making these structures attractive for use in plant studies. Although several groups have attempted other methods for isolating protoplasts such as the use of a sandwich tape method (Wu et al., 2009), the enzymatic digestion protocol is still preferred and was used in this report. Results obtained show a homogenous population of mesophyll protoplasts isolated from Arabidopsis having an approximate diameter between 30 and $60 \mu \mathrm{m}$ (Figure 1A). Although mesophyll protoplasts autofluorescence with emission between 400 and $600 \mathrm{~nm}$ due to the chlorophyll content, these were preferred over undifferentiated cultured cells since the study pertained to the perception of LPS in aerial plant tissue, i.e., specifically in plant leaves (Zeidler et al., 2010; Beets et al., 2012).

Cell viability was determined directly through the presence of cytoplasmic esterases that hydrolyze non-fluorescent FDA (Horvath, 2009) to free fluorescent fluorescein molecules within the cell (Fernandez-DaSilva and Yuffa, 2006). Results in Figure $1 \mathrm{~B}$ are represented as $100 \%$ viability for the control $(0 \mathrm{~h})$ which is composed of freshly isolated protoplasts at high yields without cell breakage or osmotic shrinkage, and a $20 \%$ relative loss in viability at $24 \mathrm{~h}$ when protoplasts are incubated at RT. Longer time periods $(>24 \mathrm{~h}$ ) resulted in a significant loss in protoplast viability as seen in other investigations (Liqing et al., 2005; Zhang and Wong, 2011). Protoplasts were thus prepared immediately prior to experimentation.

\section{Quantum Dot (Qdot)-labeling of LPS, and Characterization and Quantification of the Conjugate}

Alexa 488 hydrazide-labeling of LPS involves modification of the hydroxyl groups, particularly the O-antigen, as previously used in binding and mobility studies in mammalian cells and Arabidopsis leaves respectively. Alexa 488 is thus able to conjugate to hydrophilic LPS containing an O-antigen ('smooth' LPS), but not to hydrophobic 'rough' LPS [lipid A moiety attached to an inner/outer core or lipooligosaccharide (LOS);

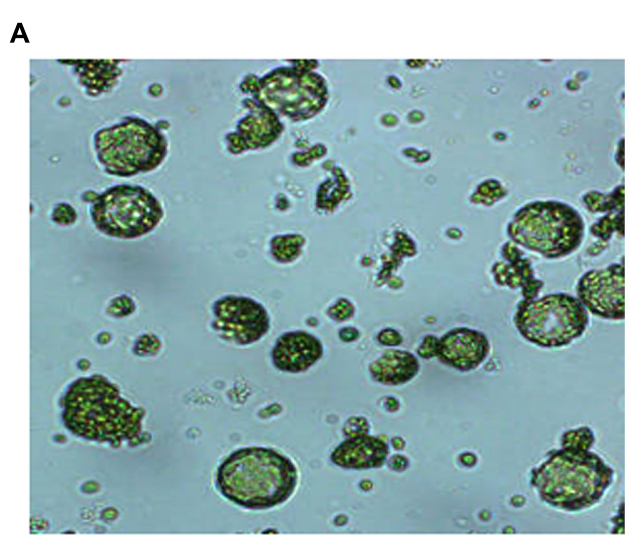

B

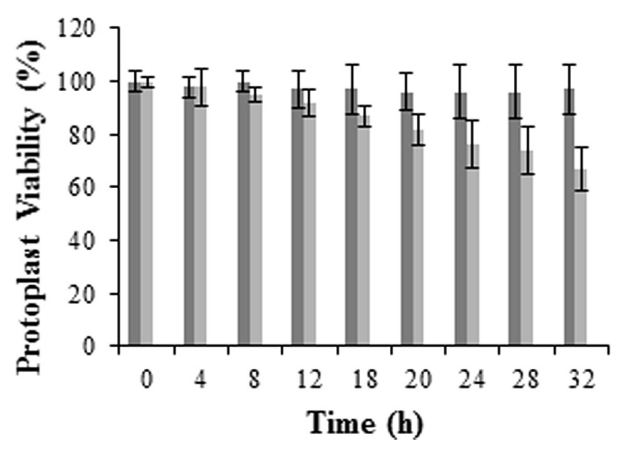

FIGURE 1 | Visualization and viability of mesophyll protoplasts isolated from Arabidopsis leaves. (A) Micrograph showing protoplasts at 100X magnification (micrographs were taken to follow the digestion process prior to washing and hence debris is still visible), and (B) histogram illustrating viability over time using the FDA stain. Dark gray bars represent total protoplasts, while light gray bars represent viable protoplasts, with error bars indicating the standard deviation of three independent biological repeats relative the control set at $100 \%$. 
Triantafilou et al., 2000]. As such, an alternative strategy employing Qdots was also included. Qdots may be synthesized as highly hydrophobic structures and thus used to target the hydrophobic lipid A, common to both LPS and LOS. Furthermore, these hydrophobic, nanometer-sized molecules can be made watersoluble and biocompatible (Chan and Nie, 1998) as illustrated

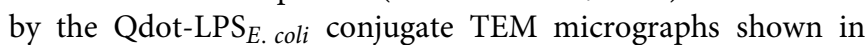
Supplementary Figures S1F-S1I in comparison to Qdots in a chloroform organic control in Supplementary Figures S1AS1C. Kim et al. (2008) reported that Qdots exist as scattered molecules in organic solution and as ordered structures when conjugated to ligands because of their resulting hydrophilicity that supports the formation of water-soluble structures. We were able to report the same for Qdots in chloroform and

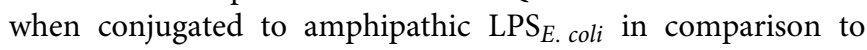
LPS in an aqueous solution. Also, such micelle formations with an approximate diameter of $100 \mathrm{~nm}$ correlate well with those reported by Betanzos et al. (2009) and Lalancette-Herbert et al. (2010).

Absorbance spectral scans were further used to characterize the Qdot-LPS ${ }_{E \text {. coli }}$ conjugate. The Qdot ${ }^{\circledR} 605$ ITK $^{\mathrm{TM}}$ nanoparticles show a peak emission wavelength of $605 \mathrm{~nm}$, and at this wavelength both Qdots and Qdots-LPS ${ }_{E}$. coli samples illustrated a peak (Supplementary Figure S2), thus demonstrating that the conjugate maintained the absorptive properties of Qdots, and so the use thereof was further supported.

Various methods exist for quantification of the molarity of Qdot-conjugates if synthesized in-house (Yu et al., 2003; Lalancette-Herbert et al., 2010). However, the current study utilized commercial Qdots without any known characteristics except for the hydrophobic nature. Also, the molar mass of commercial LPS is not known due to size heterogeneity of preparations For these reasons, the concentration of unlabeled LPS was indirectly determined by the KDO content as $5.25 \mu \mathrm{g} \mathrm{KDO}$ $\mathrm{mg}^{-1} \mathrm{LPS}_{E}$.coli and used to extrapolate the concentration of the prepared Qdot-LPS E. coli $_{\text {conjugate. }}$

\section{Optimization of Protoplast Treatment and Flow Cytometry Measurements}

An investigation into the optimal conditions for

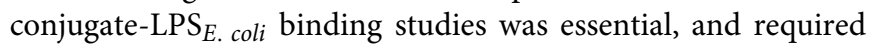
various parameters including conjugate concentration, treatment temperature, and incubation time to be explored. The optimal labeled $\mathrm{LPS}_{E \text {. coli }}$ concentration was determined over a range by studying the fluorescence response exhibited for each conjugate at a protoplast concentration of $2.5 \times 10^{5} / \mathrm{ml}$.

Using flow cytometry, events were counted for each conjugate concentration treatment and the fluorescence within the protoplast population gate was recorded. The unlabeled

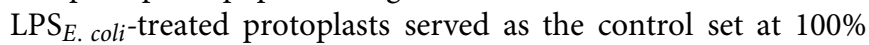
so as to easily differentiate between samples. The lowest opti-

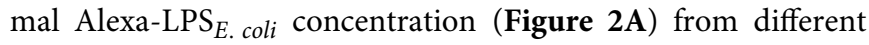
plant protoplast samples was determined to be $0.4 \mu \mathrm{g} / \mathrm{ml}$. It is unclear why a concentration of $0.75 \mu \mathrm{g} / \mathrm{ml}$ would produce a lower signal in this case, but was consistent over a number of experimental repeats. From Figure 2B, a concentration of

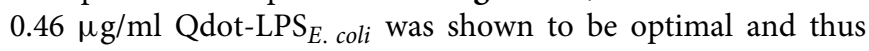

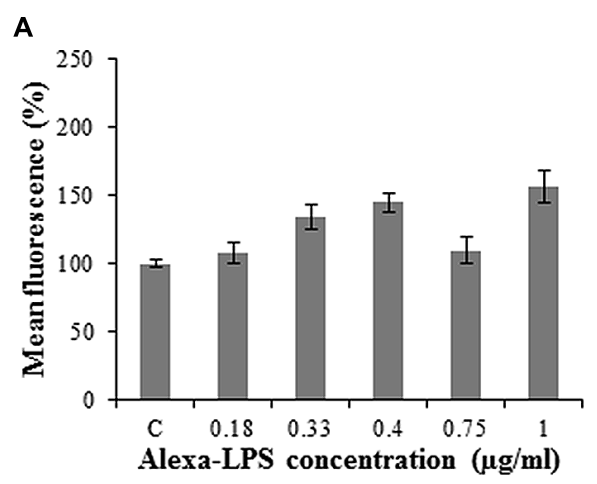

B

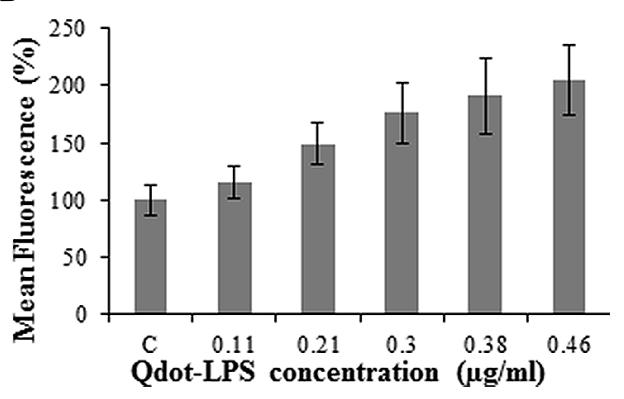

FIGURE 2 | Optimal concentration determination of LPS-conjugates in Arabidopsis protoplast binding studies incubated for 120 min with (A) Alexa-LPS $E_{E \text {. coli and (B) Qdot-LPS }}$. coli . The control (C) represents

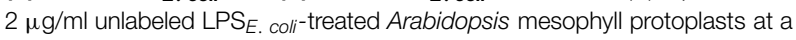
concentration of $2.5 \times 10^{5} / \mathrm{ml}$ set at $100 \%$. Each data point represents the mean of three independent experiments and error bars the standard deviation thereof.

selected for subsequent treatments as well as for comparison with the Alexa-LPS $E_{E \text { c coli }}(0.4 \mu \mathrm{g} / \mathrm{ml})$ binding studies. This concentration, although slightly higher than that of the Alexa-LPS E. coli $_{\text {, }}$ was selected since quantification of the Qdot-conjugate was extrapolated from an indirect KDO assay, and is thus not an absolute quantification. Also, both LPS conjugates were individually measured by flow cytometry, however, no fluorescence was detected (data not shown). The concentration study results cannot be compared to literature since similar previous LPSbinding studies have only been conducted in mammalian cells (Triantafilou et al., 2000; Lalancette-Herbert et al., 2010).

Post-isolation, the influence of temperature on protoplasts is related to events that occur in the plasma membrane. Changes in the fluidity of the membrane, osmotic potential, protein denaturation and expansion-induced-lysis are some of the events that occur in plant cell membranes at low and high temperatures (Thomashaw, 1999; Salvucci et al., 2001). Any such changes

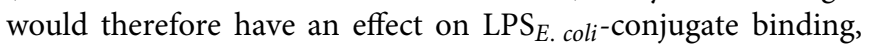
and thus the optimal incubation temperature of treated protoplasts was investigated. All samples are reported relative to untreated protoplasts and protoplasts treated with non-labeled LPS (controls) which were set at 100\%. De Filippis (1986) reported that elevated temperatures above $20^{\circ} \mathrm{C}$ produce a higher number of disrupted protoplasts. As in Supplementary Figure $\mathrm{S} 3 \mathrm{~A}$, an incubation temperature of $37^{\circ} \mathrm{C}$ could have disrupted 
the protoplast cell membrane, thereby affecting the binding of

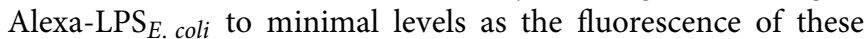
samples were not markedly higher than the untreated control and

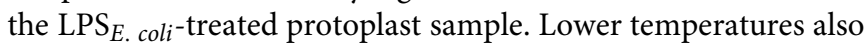
have adverse effects on the viability of protoplasts unless the cells have been acclimatized (Thomashaw, 1999), and may result from decreased enzyme activity. Incubation at $4^{\circ} \mathrm{C}$ improves protoplast half-life Zhang and Wong (2011), but upon incubation with a labeling agent, binding does not occur optimally and as seen in our results, Supplementary Figure S3B, which shows reduced

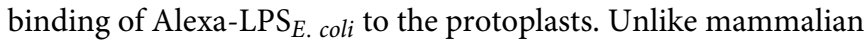
cells, plant protoplast binding was not found to be optimal at $37^{\circ} \mathrm{C}$, neither at low temperatures. As such, RT was selected for subsequent binding site studies.

Ligand binding to protoplasts can also be affected by the incubation time(s) of the investigations. With shorter incubation periods at the concentrations used in this study, as selected due to the CAC and internalization considerations mentioned earlier, optimal binding cannot be expected as ligands may still be in solution searching for potential binding sites. In contrast with longer incubation times, ligands attach to binding sites and could possibly be endocytosed into protoplasts. Such considerations stimulated investigation of the optimal incubation time for conjugate-LPS $S_{\text {. coli }}$ binding.

Figure 3 illustrates a gradual increase in Alexa-LPS ${ }_{E \text {. coli }}$ binding with time, with an ultimate sevenfold increase in fluorescence from the initial time $(10 \mathrm{~min})$ the cell membrane binds

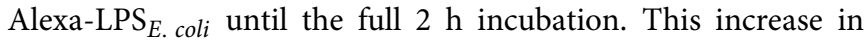
fluorescence was attributed to an increased number of bound

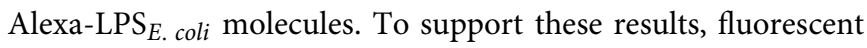
micrographs were also taken over the incubation time period. It was shown that the chosen concentration of Alexa-LPS $E_{E}$ coli optimally bound to the protoplast cell membranes between 110 and 120 min (Figure 4) which shows a completely green fluorescing protoplast cell membrane at $120 \mathrm{~min}$. It was thus determined that

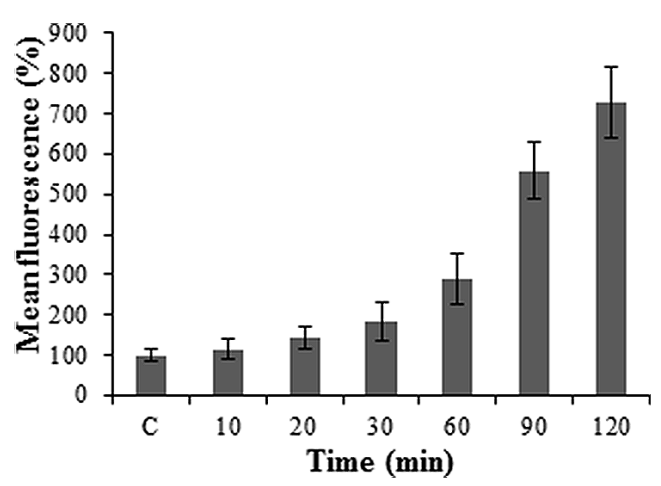

FIGURE 3 | Protoplast fluorescence changes over a $2 \mathrm{~h}$ incubation

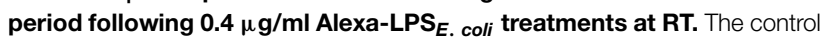

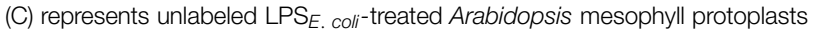
set at $100 \%$. Each data point represents the mean of three independent experiments and error bars the standard deviation thereof. The fluorescence levels remained constant after $2 \mathrm{~h}$, followed by a decrease (data not shown). an incubation time of 120 min was optimal for the cell membrane surface to become coated by fluorescing Alexa-LPS $S_{E \text {. coli }}$.

According to Figure 5, the fluorescence of the controls decrease slightly but steadily with time. This can be ascribed to a gradual loss in protoplast viability over time and subsequent degradation/disintegration of the protoplast cells as seen in Figure 1B, which indicates a slight loss of viable protoplasts at $6 \mathrm{~h}$. Figure 5 furthermore shows protoplasts treated with Qdot-LPS $_{E \text {. coli }}$ to have a high fluorescence after $2 \mathrm{~h}$ of incubation with a steep decline at $4 \mathrm{~h}$ and progressively to $6 \mathrm{~h}$. In this case, the control and non-labeled LPS treatments resulted in similar profiles and correlates well for these samples, while

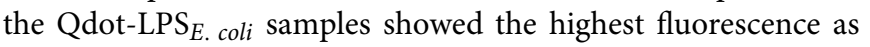
was expected. Qdots alone are highly stable fluorophores (Jaiswal and Simon, 2004; Müller et al., 2006; Betanzos et al., 2009) but the larger the shell structure (in this case due to conjugation to LPS), the lower the stability. Furthermore, fluorescence intensity is dependent on time (Sapsford et al., 2006). From these results we deduced that maximal fluorescence from conjugate-LPS $E$. coli binding occurs between 0 and $2 \mathrm{~h}$, and thus a $2 \mathrm{~h}$ incubation period was selected for all subsequent experiments.

\section{Protoplast Binding Studies}

During the optimization studies it was observed that LPS exhibited concentration-dependent aggregation (Aurell and Wistrom, 1998) that may mask epitopes of importance for binding at high concentrations. In addition, clumping of protoplasts at high concentrations due to bound LPS was also observed that negatively affected the flow cytometry detection (data not shown). Due to these experimental constraints, a classic ligand-receptor study could not be performed.

\section{Dose-Response Relationship of Labeled-LPS $_{E \text {. coli }}$ Binding to Protoplasts}

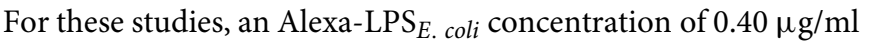

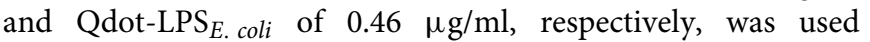
throughout. Figures 6A,B show that with an increased number of protoplasts $\left(1.2 \times 10^{5}-1.6 \times 10^{6}\right.$ protoplasts $\left./ \mathrm{ml}\right)$ and thus available binding sites, there is also an increase in the number of bound, labeled-LPS ${ }_{E}$. coli molecules. This, however, reaches a plateau at the higher protoplast concentrations, thereby generating a hyperbolic pattern. In comparison, the unlabeled LPS $E_{\text {. coli- }}$ treated protoplasts (controls) indicate a steady increase in flow cytometry measurements due to chlorophyll autofluorescence.

Here, the plateau indicates the point where the selected, optimal conjugate-ligand concentration becomes rate-limiting, thus supporting an optimal protoplast working concentration of $2 \mathrm{x}$ $10^{5} / \mathrm{ml}$ that falls within the exponential phase of dose-dependent measurements. Furthermore, this data indicates that both labeled ligands do bind to mesophyll protoplasts, regardless of whether the fluorescent conjugates were covalently or non-covalently (hydrophobically) linked. This was also confirmed when protoplasts were omitted and no fluorescence could be detected solely from the conjugates (data not shown). However, the higher fluorescence values of the Qdot-conjugate in comparison to that of autofluorescence within the exponential dose-dependent phase illustrates such labeling to be more sensitive than Alexa-labeling. 
A

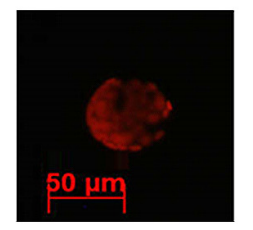

B

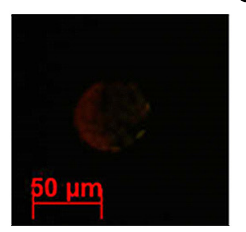

C

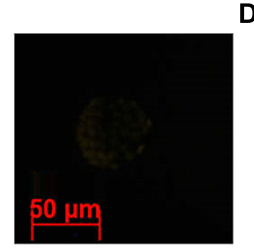

D

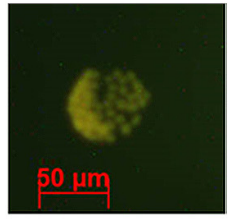

FIGURE 4 | Fluorescent micrographs indicating Arabidopsis protoplast fluorescence changes following treatment with $0.4 \mu \mathrm{g} / \mathrm{ml}$ Alexa-LPS ${ }_{E}$. coli

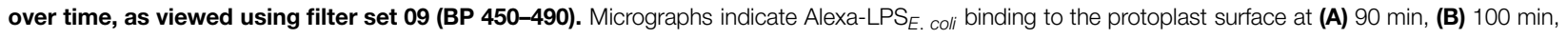
(C) $110 \mathrm{~min}$, and (D) $120 \mathrm{~min}$.

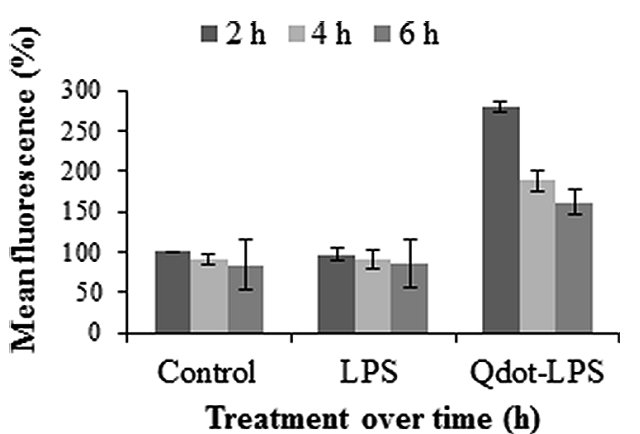

FIGURE 5 | Protoplast fluorescence changes over a $6 \mathrm{~h}$ incubation period following treatments with both unlabeled LPS $(0.4 \mu \mathrm{g} / \mathrm{ml}$

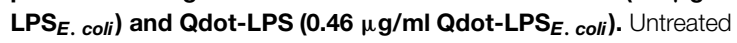
Arabidopsis protoplasts were used as a control and set to a value of $100 \%$ (at $2 \mathrm{~h})$ relative to which treated samples are reported. Three independent experiments were conducted and the error bars represent standard deviation.

\section{Reversibility of the Labeled-LPS ${ }_{E .}$ coli Binding in Protoplasts}

Reversibility of binding is one of the criteria by which binding sites/receptors are defined (Smith et al., 1983). An excess of free, competitive ligand in the order of 100 times magnitude is required to interact with the binding sites of interest followed by addition of the labeled ligand at a set protoplast concentration. Accordingly, unlabeled LPS $_{E}$. coli was added at different concentrations (in a pre-incubation step, Triantafilou et al., 2000), followed by addition of the respectively labeled LPS $_{E .}$ coli ${ }^{-}$ conjugates at a protoplast concentration of $2 \times 10^{5} / \mathrm{ml}$ in order to elucidate whether the ligand interacts reversibly with a binding site/receptor.

The relative fluorescence of the conjugate (both Alexa- and Qdot- LPS $\left._{E \text {. coli }}\right)$ treatment alone is markedly higher in the case of the Qdot-labeled studies, but less pronounced in the Alexa-labeled studies. This may be ascribed to a more sensitive response from a more superior labeling strategy. The obtained results, however, showed an attenuation of fluorescence upon increase in the concentration of unlabeled $\mathrm{LPS}_{E \text {. coli }}$ treatment. This illustrates that free LPS competes with labeled PPS $_{E \text {. coli }}$ (both Alexa- and Qdot-labeled binding), and thus the response obtained for the three competitive concentrations is representative of the total ligand binding. In this regard, Gross et al.

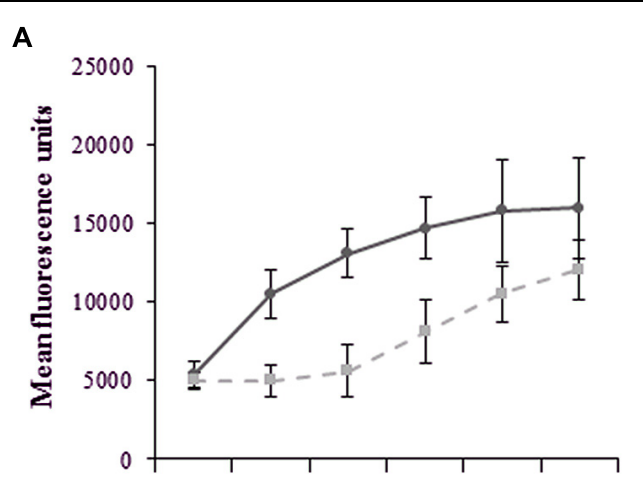

B

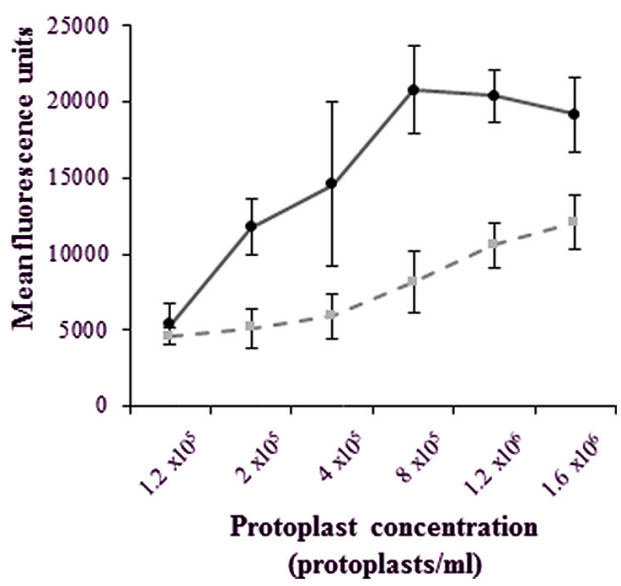

FIGURE 6 | Dose-dependent kinetics illustrating a plateau in the mean fluorescence even with an increase in the total number of binding sites on an increasing number of protoplasts following a $2 \mathrm{~h}$ treatment with (A) Alexa-LPS $E_{E}$ coli (measured at 500-560 nm) and

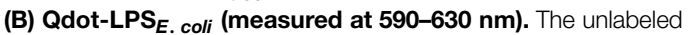

$L_{\text {LPS }}$ coli-treated protoplasts as controls (dashed lines) are compared to treated protoplasts (solid lines), with the error bars representing the standard deviation of three independent experiments.

(2005) also reported that the uptake of LPS could be outcompeted by the addition of an excess of unlabeled LPS in N. tabacum cells as was observed in Figure 7. Upon labeled LPS ${ }_{E \text {. coli }}$ treatment, the conjugate binds to the few unbound/available binding sites and thus a low signal intensity is obtained at the higher concentrations of unlabeled LPS treatment. Triantafilou et al. (2000) similarly investigated specificity, with 100x unlabeled 
A

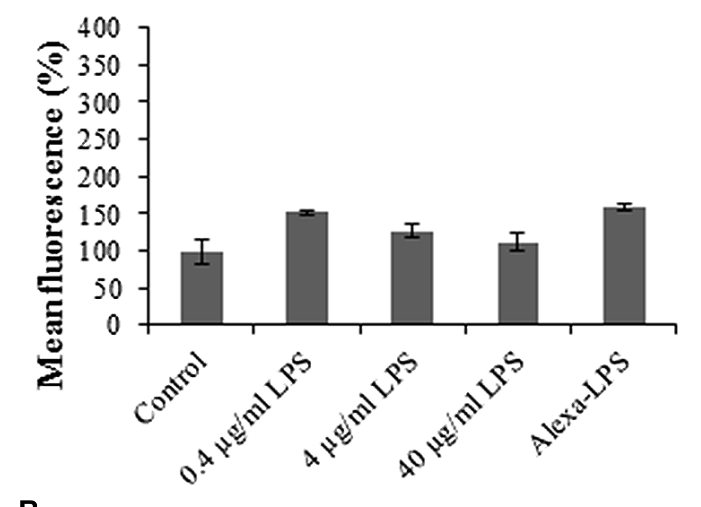

B

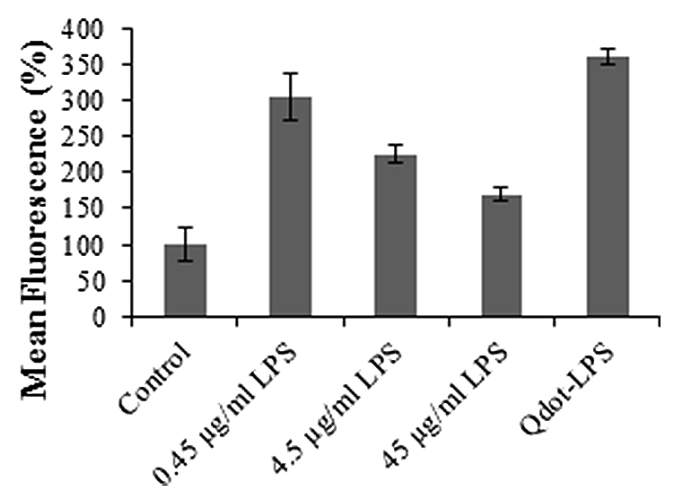

FIGURE 7 | Graphs illustrating binding reversibility of LPS-conjugates to mesophyll Arabidopsis binding sites. Protoplasts were pre-incubated

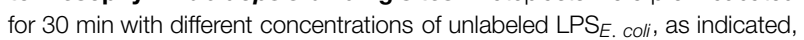

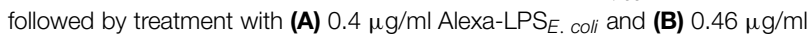

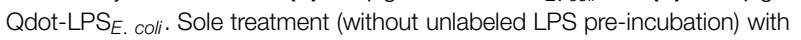
labeled LPS-conjugates also served as positive controls. The negative

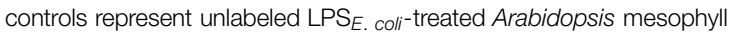
protoplasts set at $100 \%$, with error bars representing standard deviation of three independent biological repeats.

LPS pre-treatment inhibiting the binding of Alexa-LPS ${ }_{E \text {. coli, }}$ thus proving specific binding to $\mathrm{CHO}$ cells. Scott et al. (2009) also showed that mouse hepatocytes are blocked due to pretreatment with LPS. Although the studies were in mammalian cells, the same principle applies to plant cells. The response thus determined in Figure 7 indicates reversible binding, with Qdot fluorophores proving to be a more sensitive labeling strategy.

Ultimately, these results with both labeled LPS-conjugates also pose the question as to whether unlabeled LPS pre-treatment leads to internalization of binding sites by ligand-dependent receptor-mediated endocytosis (RME), where LPS-binding sites

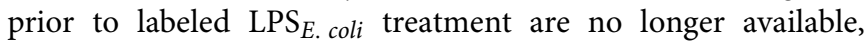
and hence fewer binding sites. Alternatively, if not endocytosed, most binding sites are most likely occupied by the high concentrations of unlabeled $\mathrm{LPS}_{E \text {. coli }}$. Upon labeled LPS $_{E \text {. coli }}$ treatment, the conjugate binds to the few available (unbound) binding sites/receptors and a low signal intensity is obtained.

\section{Exo- and Endocytosis Inhibitors in Labeled LPS $_{E \text {. coli Binding Site Studies }}$}

Endocytosis occurs when molecules and/or receptors are translocated into the cell cytoplasm from the extracellular environment. Besides its role in signal attenuation by regulating the levels of ligand or available receptors, the process also exists in all cells so as to transport large polar molecules past the hydrophobic cell membrane and into the cell (Emans et al., 2002; Irani and Russinova, 2009). Both pinocytosis/fluid phase endocytosis (FPE) and/or RME are capable of receptor internalization (Aniento and Robinson, 2005). FPE is the uptake that occurs without clathrincoated caveolae while RME requires clathrin-coated caveolae (Emans et al., 2002). Such endocytosis has been shown in the interaction of flg22 with FLS2, a LRR-RLK (Robatzek et al., 2006; Geldner and Robatzek, 2008; Beck et al., 2012a,b). Here, translocation of the complex from early endosomes to recycling endosomes for the FLS2 co-receptors, Brassinosteroid-Insensitive 1 (BRI1) and BRI1-associated-receptor kinase1 (BAK1), which are constitutive ligand receptors, occurs (Geldner and Robatzek, 2008; Frei dit Frey and Robatzek, 2009; Antolin-Llovera et al., 2012). Alternatively, endosomes marked for degradation in vacuoles by lytic enzymes commonly occurs in the case of ligandinduced RME of flg22-FLS2 (Geldner and Robatzek, 2008; Frei dit Frey and Robatzek, 2009; Irani and Russinova, 2009). Here, we report on Wortmannin and BFA as compounds capable of inhibiting endo- and exocytosis in plant cells, where the use of protoplasts is a feasible option to study the mode of endocytosis, albeit not, of LPS binding sites/receptors in plants. In this regard, BFA, is capable of inhibition of exocytosis (recycling) by targeting adenosine diphosphate ribosylation factor (ARF) guanine nucleotide exchange factor (GEF; Frei dit Frey and Robatzek, 2009), while Wortmannin, a potent endocytosis inhibitor, prevents the uptake of both receptors and ligands into the cell by specifically inhibiting phosphatidylinositol 3-kinase (PI3K; Shpetner et al., 1996; Wang et al., 2009). Endocytosis and signaling are, furthermore, said to be functionally interconnected as they share common molecular components on the plasma membrane (Geldner and Robatzek, 2008; Irani and Russinova, 2009; Beck et al., 2012a).

It is hypothesized that initial LPS-conjugate binding takes place on the protoplast surface membrane and remains on surface binding sites/receptors upon Wortmannin treatment (Figures $\mathbf{8 A}, \mathbf{B}$ ) as a consequence of the inhibitor's ability to prevent endocytosis. Thus only "initial binding sites" are measured as seen by the slight increased fluorescence of cotreated samples compared to the negative control, but much lower than the positive control. BFA, on the other hand, prevents exocytosis and thus inhibits recycling of such binding sites/receptors, leading to a decrease in fluorescence (compared to the positive controls) over time (Figures 8A,B), since again most likely only "initial binding sites" are measured.

Results obtained using these inhibitors exhibit characteristics of binding and perception of LPS E. coli $_{\text {as shown by reduced levels }}$ in fluorescence of the co-treated samples in comparison to those treated with only LPS conjugates. This suggests that when LPS binds to protoplasts, it may be internalized into the cell by endocytosis leading to transiently reduced levels of the binding site 
A
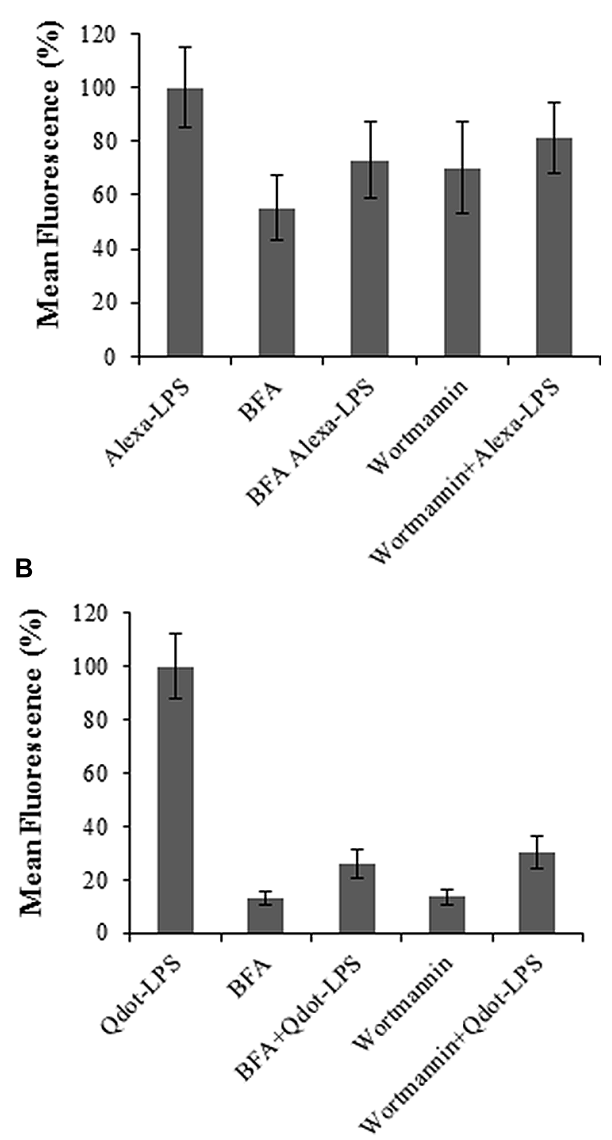

FIGURE 8 | The role of exo- (BFA) and endocytosis (Wortmannin) inhibitors in protoplasts treated with labeled LPS-conjugates. Samples were co-treated simultaneously with either inhibitor and (A) $0.4 \mu \mathrm{g} / \mathrm{ml}$

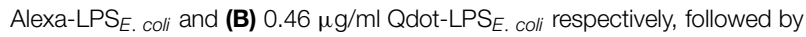
incubation at RT for 120 min. Sole treatment with each LPS-conjugate served a positive control and set to $100 \%$, while BFA and Wortmannin sole treatments were included as negative controls. Error bars represent the standard deviation of three independent biological repeats.

protein(s) on the surface. Gross et al. (2005) reported the specific recognition of LPS from X. campestris pv. campestris $\left(\right.$ LPS $\left._{X . c . c}\right)$ in $N$. tabacum cells. LPS was shown to be internalized into the cells when labeled with FITC in a temperature- and energy-dependent manner. Furthermore, endocytosis in plant cells was reported in the same study with the use of amantidine, an inhibitor of RME. Immunolocalization studies further proved co-localization of the LPS-elicitor with endosomal structures. In contrast, Zeidler et al. (2010) did not observe internalization during mobility studies of Alexa-labeled LPS. minnesota in Arabidopsis leaves.

When looking at the overall profile of Figure 8 when compared to the work of Beck et al. (2012b), the BFA inhibition studies show a more sensitive response than the Wortmannin counterpart. This poses the question as to whether the recognition and subsequent endocytic route in this case may more resemble that of a non-activated ligand status (as is the case for the non-activated FLS2 receptor), i.e., a constitutive recycling.
However, when comparing the profiles between Figures 8A,B specifically, it could be extrapolated that the Qdot-labeled studies present results which more resemble an activated ligand status in terms of endo- and exocytosis routes. This possibly highlights the difference and importance of the LPS-labeling strategy. Since the binding site/receptor and co-receptor complexes are not known in this case, the data and interpretation is currently speculative.

\section{Conclusion}

Here, we demonstrate the use of Qdots, reported by Betanzos et al. (2009), as a preferential LPS-labeling strategy in comparison to previously used alternatives in binding studies. Triantafilou et al. (2000) appraised Alexa-labeling of LPS as a superior strategy in comparison to FITC, and so we compared Alexa to Qdots. The hydrophobic nanoparticles were successfully conjugated to $\mathrm{LPS}_{E \text {. coli }}$, and resulted in sensitive and bio-compatible Qdot-ligand complexes as previously reported (Sapsford et al., 2006; Yu et al., 2006a,b; Betanzos et al., 2009; Barr et al., 2010). Furthermore, another clear disadvantage of Alexa-labeling is the requirement of smooth LPS for covalent chemical modification which is not the case with Qdot-labeling. This illustrates the superiority of the latter for use in variant, including rough, LPS-binding site/receptor studies in plants.

Current models for MAMP perception predict the existence of PRRs (Zipfel, 2014). Although there is overlap in the cellular responses induced by LPS and other MAMPs that signal through surface receptors, a similar receptor/receptor complex has, however, not yet been reported for LPS. In this regard, Sanabria et al. (2012) proposed a role for S-domain RLKs in LPS perception and subsequent signal transduction events.

In general, the structural features of a ligand that determines the affinity for a receptor may be distinct from those which determine activity. Hence, the possibility exists that the carbohydrate and lipid moieties of LPS may be perceived by individual albeit interconnected or linked mechanisms (Madala et al., 2012). In this study, it was shown for the first time that specific binding sites for LPS do occur on Arabidopsis mesophyll protoplast surfaces using both Alexa-LPS $S_{\text {. coli }}$ and Qdot-LPS $S_{\text {. coli }}$. Wortmannin investigations showed that LPS-binding most likely involves ligand-induced endocytotic process, while BFA studies furthermore hinted toward exocytosis-mediated recycling of the binding sites that may function in concert in the perception of LPS.

\section{Author Contributions}

LP and ID designed the research; LM performed the research; and LP, ID, and LM wrote the paper.

\section{Acknowledgments}

LP would like to acknowledge financial support received from the National Research Foundation (Reference: 
SUR200906090000587; Grant No: 70978) and the Faculty Research Council, University of Johannesburg. LM acknowledges the University of Johannesburg for the New Generation Scholarship. Drs. H.-A. Byth-Illing and M. Meyer are thanked for technical assistance and operation of the flow cytometer.

\section{References}

Albright, S., Afrawal, P., and Jain, N. U. (2009). NMR spectral mapping of Lipid A molecular patterns affected by interaction with the innate immune receptor CD14. Biochem. Biophys. Res. Commun. 378, 721-726. doi: 10.1016/j.bbrc.2008.11.113

Altenbach, D., and Robatzek, S. (2007). Pattern recognition receptors: from the cell surface to intracellular dynamics. Mol. Plant Microbe Interact. 20, 1031-1039. doi: 10.1094/MPMI-20-9-1031

Aniento, F., and Robinson, D. G. (2005). Testing for endocytosis in plants. Protoplasma 226, 3-11. doi: 10.1007/s00709-005-0 101-y

Antolin-Llovera, M., Reid, M. K., Binder, A., and Parniske, M. (2012). Receptorkinase signalling in plant-microbe interactions. Annu. Rev. Phytopathol. 50, 45-73. doi: 10.1146/annurev-phyto-081211-173002

Aurell, C. A., and Wistrom, A. O. (1998). Critical aggregation concentrations of Gram-negative bacterial lipopolysaccharides (LPS). Biochem. Biophys. Res. Commun. 253, 119-123. doi: 10.1006/bbrc.19 98.9773

Barr, T. A., Krembuszewski, M., Gupta, M., Gray, D., and Mareque-Rivas, J. C. (2010). Quantum dot decorated with pathogen associated molecular patterns as fluorescent synthetic pathogen models. Mol. Biosyst. 6, 1572-1575. doi: 10.1039/c002066d

Beck, M., Heard, W., Mbengue, M., and Robatzek, S. (2012a). The ins and outs of pattern recognition receptors at the cell surface. Curr. Opin. Plant Biol. 15, 367-374. doi: 10.1016/j.pbi.2012.05.004

Beck, M., Zhou, J., Faulkner, C., MacLean, D., and Robatzek, S. (2012b). Spatiotemporal cellular dynamics of the Arabidopsis flagellin receptor reveal activation status-dependent endosomal sorting. Plant Cell 24, 4205-4219. doi: 10.1105/tpc.112.100263

Beets, C., Huang, J.-C., Madala, N. E., and Dubery, I. A. (2012). Biosynthesis of camalexin in Arabidopsis thaliana in response to lipopolysaccharide elicitation: a gene-to-metabolite study. Planta 236, 261-272. doi: 10.1007/s00425-0121606-1

Betanzos, C. M., Gonzalez-Moa, M., Johnston, S. A., and Svarovsky, S. A. (2009). Facile labelling of lipoglycans with quantum dots. Biochem. Biophys. Res. Commun. 380, 1-4. doi: 10.1016/j.bbrc.2008.12.167

Chan, W. C. W., and Nie, S. M. (1998). Quantum dot bioconjugates for ultrasensitive nonisotopic detection. Science 281, 2016-2019. doi: 10.1126/science.281.5385.2016

Cheng, Y., and Bélanger, R. R. (2000). Protoplast preparation and regeneration from spores of the biocontrol fungus Pseudozyma flocculosa. FEMS Microbiol. Lett. 190, 287-291. doi: 10.1111/j.1574-6968.2000.tb09 300.x

Chinchilla, D., Zipfel, C., Robatzek, S., Kemmerling, B., Nürnberger, T., and Jones, J. D. G., et al. (2007). A flagellin-induced complex of the receptor FLS2 and BAK1 initiates plant defence. Nature 448, 497-500. doi: 10.1038/nature 05999

Coventry, H. S., and Dubery, I. A. (2001). Lipopolysaccharides from Burkholderia cepacia contribute to an enhanced defensive capacity and the induction of pathogenesis-related proteins in Nicotiana tabacum. Phys. Mol. Plant Pathol. 58, 149-158. doi: 10.1006/pmpp.2001.0323

De Filippis, L. F. (1986). The effects off temperature, light, and metal ions on (Avena sativa L.) mesophyll protoplasts. Biochem. Phys. Pflanzen 181, 29-38. doi: 10.1016/S0015-3796(86)80017-8

Doležel, J., Greilhuber, J., and Suda, J. (2007). Estimation of nuclear DNA content in plants using flow cytometry. Nat. Protoc. 2, 2233-2244. doi: 10.1038/nprot.2007.310

Dubery, I. A., Sanabria, N. M., and Huang, J.-C. (2012). "Nonself perception in plant innate immunity," in Self and Nonself: Advances in Experimental Medicine

\section{Supplementary Material}

The Supplementary Material for this article can be found online at: http://journal.frontiersin.org/article/10.3389/fpls. 2015.00335/abstract

and Biology, Vol. 783, ed. C. López-Larrea (Austin, TX: Landes Bioscience; Berlin: Springer), 79-107.

Emans, N., Zimmerman, S., and Fischer, R. (2002). Uptake of a fluorescent marker in plant cells is sensitive to Brefeldin A and Wortmannin. Plant Cell 14, 71-86. doi: $10.1105 /$ tpc.010339

Erbs, G., and Newman, M.-A. (2012). The role of lipopolysaccharide and peptidoglycan, two glycosylated bacterial microbe-associated molecular patterns (MAMPs) in plant innate immunity. Mol. Plant Pathol. 13, 95-104. doi: 10.1111/j.1364-3703.2011.00730.x

Fernandez-DaSilva, R., and Yuffa, M. (2006). Viability in protoplasts and cell suspensions of Coffea arabica cv. Catimor. E. J. Biotech. 9, 593-597. doi: 10.2225/vol9-issue5-fulltext-4

Frei dit Frey, N., and Robatzek, S. (2009). Trafficking vesicles: pro or contra pathogens. Curr. Opin. Plant Biol. 12, 1-7.

Galbraith, D. W. (1994). Chapter 31: Flow cytometry and sorting of plant protoplasts and cells. Methods Cell Biol. 42, 539-561. doi: 10.1016/S0091679X(08)61094-8

Geldner, N., and Robatzek, S. (2008). Plant receptors go endosomal: A moving view on signal transduction. Plant Phys. 147, 1565-1574. doi: 10.1104/pp.108.120287

Gerber, I. B., Laukens, K., Witters, E., and Dubery, I. A. (2006). Lipopolysaccharideresponsive phosphoproteins in Nicotiana tabacum cells. Plant Physiol. Biochem. 44, 369-379. doi: 10.1016/j.plaphy.2006.06.015

Gerber, I. B., Zeidler, D., Durner, J., and Dubery, I. A. (2004). Early perception response of Nicotiana tabacum cells in response to lipopolysaccahride from Burkholderia cepacia. Planta 218, 647-657. doi: 10.1007/s00425-003-1142-0

Gross, A., Kapp, D., Nielsen, T., and Niehaus, K. (2005). Endocytosis of Xanthomonas campestris pathovar campestris lipopolysaccharides in non-host plant cells of Nicotiana tabacum. New Phytol. 165, 215-226. doi: 10.1111/j.14698137.2004.01245.x

He, P., Shan, L., and Sheen, J. (2006). The use of protoplasts to study innate immune responses. Methods Mol. Biol. 354, 123-134. doi: 10.1385/1-59259-96 6-4:1

Horvath, E. (2009). Protoplast isolation from Solanum lycopersicum L. leaf tissues and their response to short-term $\mathrm{NaCl}$ treatment. Acta Biol. Szeg. 53, 83-86.

Irani, N. G., and Russinova, E. (2009). Receptor endocytosis and signaling in plants. Curr. Opin. Plant Biol. 12, 653-659. doi: 10.1016/j.pbi.2009. 09.011

Jaiswal, J. K., and Simon, S. M. (2004). Potentials and pitfalls of fluorescent quantum dots for biological imaging. Trends Cell Biol. 14, 497-504. doi: 10.1016/j.tcb.2004.07.012

Karkhanis, Y. D., Zeltner, J. Y., Jackson, J. J., and Carlo, D. J. (1978). A new and improved microassay to determine 2-keto-3-deoxyoctonate in lipopolysaccharide of gram-negative bacteria. Anal. Biochem. 85, 595-601. doi: 10.1016/00032697(78)90260-9

Kim, J., Park, K., and Huhn, S. K. (2008). Effect of hyaluronic acid molecular weight on the morphology of quantum dot-hyaluronic acid conjugates. Int. J. Biol. Macromol. 42, 41-45. doi: 10.1016/j.ijbiomac.2007.09.002

Lalancette-Herbert, M., Moquin, A., Choi, A. O., Kriz, J., and Maysinger, D. (2010). Lipopolysaccharide-QD micelles induce marked induction of TLR2 and lipid droplet accumulation in olfactory bulb microglia. Mol. Pharm. 7, 1183-1194. doi: $10.1021 / \mathrm{mp} 1000372$

Liqing, Z., Bochu, W., Jing, Z., Lingxi, C., Chuanyun, D., and Chuanren, D. (2005). Protoplast isolation of callus in Echinacea augustofolia. Colloids Surf. B Biointerfaces 44, 1-5. doi: 10.1016/j.colsurfb.2005.05.002

Madala, N. E., Leone, M. R., Molinaro, A., and Dubery, I. A. (2011). Deciphering the structural and biological properties of the lipid A sub-component of lipopolysaccharides from Burkholderia cepacia strain ASP B 2D, in Arabidopsis thaliana. Glycobiology 21, 184-194. doi: 10.1093/glycob/cwq146

Madala, N. E., Molinaro, A., and Dubery, I. A. (2012). Distinct carbohydrate and lipid-based molecular patterns within lipopolysaccharides from 
Burkholderia cepacia contribute to defense-associated differential gene expression in Arabidopsis thaliana. Innate Immun. 18, 140-154. doi: $10.1177 / 1753425910392609$

Mishina, T. E., and Zeier, J. (2007). Pathogen-associated molecular pattern recognition rather than development of tissue necrosis contributes to bacterial induction of systemic acquired resistance in Arabidopsis. Plant J. 50, 500-513. doi: 10.1111/j.1365-313X.2007.03067.x

Morales-Betanzos, C., Gonzalez-Moa, M., and Svarovsky, S. A. (2011). A method for unobtrusive labelling of lipopolysaccharides with quantum dots. Methods Mol. Biol. 739, 113-122. doi: 10.1007/978-1-61779-102-4_10

Müller, F., Houben, A., Barker, P., Xiao, Y., Käs, A., and Melzer, M. (2006). Quantum dots - a versatile tool in plant science? J. Nanobiotechnol. 4, 1-5. doi: 10.1186/1477-3155-4-1

Newman, M., Dow, J. M., Molinaro, A., and Parilli, M. (2007). Priming, induction and modulation of plant defence responses by bacterial lipopolysaccharides. J. Endotoxin. Res. 13, 69-84. doi: 10.1177/0968051907079399

Nürnberger, T., Brunner, F., Kemmerling, B., and Piater, L. (2004). Innate immunity in plants and animals: striking similarities and obvious differences. Immunol. Rev. 198, 249-266. doi: 10.1111/j.0105-2896.2004.0 119.x

Odeyale, C. O., and Kang, Y. H. (1988). Biotinylation of bacterial lipopolysaccharide and its applications to electron microscopy. J. Histochem. Cytochem. 36, 1131-1137. doi: 10.1177/36.9.3136207

Piater, L. A., Nürnberger, T., and Dubery, I. A. (2004). Identification of a lipopolysaccharide responsive erk-like MAP kinase in tobacco leaf tissue. Mol. Plant Pathol. 5, 331-341. doi: 10.1111/j.1364-3703.2004.00234.x

Robatzek, S., Chinchilla, D., and Boller, T. (2006). Ligand-induced endocytosis of the pattern recognition receptor FLS2 in Arabidopsis. Genes Dev. 20, 537-542. doi: 10.1101/gad.366506

Salvucci, M. E., Osteryoung, K. W., Crafts-Brandner, S. J., and Vierling, E. (2001). Exceptional sensitivity of RUBISCO Activase to thermal denaturation in vitro and in vivo. Plant Physiol. 127, 1053-1064. doi: 10.1104/pp.010357

Sanabria, N., Goring, D., Nürnberger, T., and Dubery, I. A. (2008). Self/nonself perception and recognition mechanisms in plants: a comparison of selfincompatibility and innate immunity. New Phytol. 178, 503-514. doi: 10.1111/j.1469-8137.2008.02403.x

Sanabria, N. M., van Heerden, H., and Dubery, I. A. (2012). Molecular characterisation and regulation of a Nicotiana tabacum S-domain receptor-like kinase gene induced during an early rapid response to lipopolysaccharides. Gene 501, 39-48. doi: 10.1016/j.gene.2012.03.073

Sapsford, K. E., Pons, T., Medintz, I. L., and Mattoussi, H. (2006). Biosensing with luminescent semiconductor quantum dots. Sensors 6, 925-953. doi: $10.3390 /$ s6080925

Sasaki, H., and White, S. H. (2008). Aggregation behaviour of an ultra-pure lipopolysaccharide that stimulates TLR-4 receptors. Biophys. J. 95, 986-993. doi: 10.1529/biophysj.108.129197

Scott, M. J., Liu, S., Shapiro, R. A., Vodovitz, Y., and Billiar, T. R. (2009). Endotoxin uptake in mouse liver is blocked by endotoxin pretreatment through a suppressor of cytokine signalling-1-dependent mechanism. Hepatology 49, 1695-1708. doi: 10.1002/hep.22839

Shpetner, H., Joly, M., Hartley, D., and Corvera, S. (1996). Potential sites of PI-3 kinase function in the endocytic pathway revealed by the PI-3 kinase inhibitor, Wortmannin. J. Cell Biol. 132, 595-605. doi: 10.1083/jcb.132.4.595

Silipo, A., Molinaro, A., Sturiale, L., Dow, J. M., Erbs, G., Lanzetta, R., et al. (2005). The elicitation of plant innate immunity by lipopolysacchride of Xanthomonas campestris. J. Biol. Chem. 280, 33660-33668. doi: 10.1074/jbc.M5062 54200

Smith, E. L., Hill, R. L., Lehman, I. R., Lefkowitz, R. J., Handler, P., and White, A. (1983). Principles of Biochemistry: General Aspects, 7th Edn, Chap. 14. New York, NY: Mcgraw-Hill Book Company, 289-298.
Thomashaw, M. F. (1999). Plant cold acclimation: Freezing tolerance genes and regulatory mechanisms. Annu. Rev. Plant Physiol. Plant Mol. Biol. 50, 571-599. doi: 10.1146/annurev.arplant.50.1.571

Triantafilou, K., Triantafilou, M., and Dedrick, R. L. (2001). Interactions of bacterial lipopolysaccharide and peptidoglycan with a $70 \mathrm{kDa}$ and an $80 \mathrm{kDa}$ protein on the cell surface of CD14 ${ }^{+}$and CD14- cells. Hum. Immunol. 62, 50-63. doi: 10.1016/S0198-8859(00)00222-6

Triantafilou, K., Triantafilou, M., and Fernandez, N. (2000). Lipopolysaccharide (LPS) labelled with Alexa 488 hydrazide as a novel probe for LPS binding studies. Cytometry 41, 316-320. doi: 10.1002/1097-0320(20001201)41:4<316::AIDCYTO10>3.0.CO;2-Z

Van Loon, L. C., Bakker, P. A. H. M., and Pieterse, C. M. J. (1998). Systemic resistance induced by rhizophere bacteria. Annu. Rev. Phytopath. 36, 453-483. doi: 10.1146/annurev.phyto.36.1.453

Venis, M. (1985). "Methods in receptor research," in Hormone Binding Sites in Plants: Research Notes in the Biosciences, ed. M. Wilkins (New York, NY: Longman), 24-40.

Wang, J., Cai, Y., Miao, Y., Lam, S. K., and Jiang, L. (2009). Wortmannin induces homotypic fusion of plant prevacuolar compartments. J. Exp. Bot. 60, 30753083. doi: 10.1093/jxb/erp136

Wu, F., Shen, S., Lee, L., Lee, S., Chan, M., and Lin, C. (2009). Tape-Arabidopsis Sandwich - a simpler Arabidopsis protoplast isolation method. Plant Methods 5:16. doi: 10.1186/1746-4811-5-161

Yoo, S., Cho, Y., and Sheen, J. (2007). Arabidopsis mesophyll protoplasts: a versatile cell system for transient gene expression analysis. Nat. Protoc. 2, 1565-1572. doi: 10.1038/nprot.2007.199

Yu, G., Lian, J., He, Z., and Sun, M. (2006a). Quantum Dot-mediated detection of $\gamma$-aminobutyric acid binding sites on the surface of living pollen protoplasts in tobacco. Chem. Biol. 13, 723-731. doi: 10.1016/j.chembiol.2006.05.007

Yu, W. W., Chang, E., Drezek, R., and Colvin, V. L. (2006b). Water-soluble quantum dots for biomedical applications. Biochem. Biophys. Res. Commun. 348, 781-786. doi: 10.1016/j.bbrc.2006.07.160

Yu, W. W., Qu, L., Guo, W., and Peng, X. (2003). Experimental determination of the extinction coefficient of CdTe, Cdse and CdS nanocrystals. Chem. Materials 15, 2854-2860. doi: $10.1021 / \mathrm{cm} 034081 \mathrm{k}$

Zeidler, D., Dubery, I. A., Schmitt-Kopplin, P., von Rad, U., and Durner, J. (2010). Lipopolysaccharide mobility in leaf tissue of Arabidopsis thaliana. Mol. Plant Pathol. 11, 747-755. doi: 10.1111/j.1364-3703.2010.00638.x

Zeidler, D., Zähringer, U., Gerbe, I. B., Dubery, I. A., Hartung, T., Bors, W., et al. (2004). Innate immunity in Arabidopsis thaliana: Lipopolysaccharides activate nitric oxide synthase (NOS) and induce defense genes. Proc. Natl. Acad. Sci. U.S.A. 101, 15811-15816. doi: 10.1073/pnas.0404536101

Zhang, X., and Wong, S. M. (2011). Development of a cell sorting procedure to increase the sensitivity of detection of protein-protein interactions in plant protoplasts. J. Virol. Methods 173, 347-352. doi: 10.1016/j.jviromet.2011.03.007

Zipfel, C. (2009). Early molecular events in PAMP-triggered immunity. Curr. Opin. Plant Biol. 12, 414-420. doi: 10.1016/j.pbi.2009.06.003

Zipfel, C. (2014). Plant pattern-recognition receptors. Trends Immunol. 35, 345351. doi: 10.1016/j.it.2014.05.004

Conflict of Interest Statement: The authors declare that the research was conducted in the absence of any commercial or financial relationships that could be construed as a potential conflict of interest.

Copyright (c) 2015 Mgcina, Dubery and Piater. This is an open-access article distributed under the terms of the Creative Commons Attribution License (CC BY). The use, distribution or reproduction in other forums is permitted, provided the original author(s) or licensor are credited and that the original publication in this journal is cited, in accordance with accepted academic practice. No use, distribution or reproduction is permitted which does not comply with these terms. 